\title{
Reading mathematical exercises: preliminary results
}

Deolinda Correia, Isabel Hub Faria and Paula Luegi

Laboratório de Psicolinguística, Universidade de Lisboa, Portugal

https://doi.org/10.36505/ExLing-2008/02/0019/000078

\begin{abstract}
This research on reading comprehension is concerned with linguistic complexity processing and solving of mathematical exercises by 95 Portuguese students aged 9 to 15 years, attending one of the three basic school levels. Exercises were selected from the full set of national examinations (from 2000 till 2007), covering different mathematical areas. Experimental task was to present subjects with an exercise text followed by a possible result which they had to evaluate as a good or bad answer. Preliminary results indicate that although the extension of the exercise text and of the answer influences the time spent reading and solving the problem, it does not necessarily make the resolution of the exercise harder.
\end{abstract}

Key words: mathematical exercises processing/solving and reading

\section{Introduction}

The present study is part of a larger research project on reading comprehension of words, sentences and texts that is taking place at the University of Lisbon.

This paper particularly focuses on mathematical exercises resolution by subjects attending the three basic school levels.

The Portuguese Ministry of Education (ME) has pointed out as one of the major reasons for the lack of success in mathematics evaluation the difficulties of basic school students in reading and comprehending the examinations' texts. However, these declarations were never rigorously justified, since until the present, no studies revealed the reading behaviours of the subjects while processing mathematical exercises. Studies in this area (Hegarty, Mayer and Green 1992; Thompson 1992; Suppes 1990) point out mainly to factors associated with mathematical competence.

We selected from the whole set of mathematics national examinations the set of stimuli used in our experiment.

The structural diversity under observation maintains the thematic domains and the types of operations of the official ME program in mathematics for each basic level.

In this study we analysed the 'yes/no' answers provided by 95 students to 'true/false' results of 60 exercises. Each result was shown on the screen after the participant had read the exercise text.

ExLing 2008: Proceedings of 2nd Tutorial and Research Workshop on Experimental Linguistics, 25-27 August 2008, Athens, Greece 


\section{Experiment}

\section{Methodology}

Material

Exercises used as experimental stimuli have been selected from the full set of national examinations (from 2000 till 2007).

Exercises cover different areas which are defined by the national mathematical educational programs: numbers and operations, shapes and space, measures and dimensions ( $4^{\text {th }}$ year); numbers and calculus, statistics and probabilities, proportionality ( $6^{\text {th }}$ year); numbers and calculus, statistics and probabilities, algebra, geometry $\left(9^{\text {th }}\right.$ year $)$, and require the following aspects of mathematical competence: concepts and procedures, reasoning, problems solving and communication. The nature of the exercises used as stimuli was unimodal (only text) and bimodal (text and image).

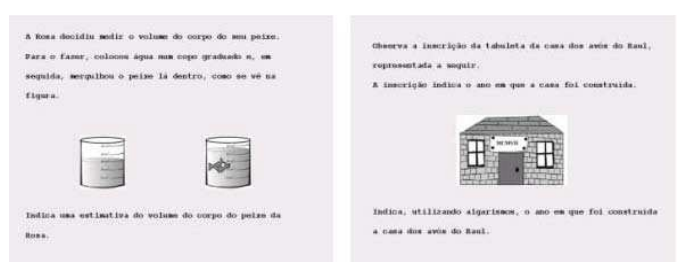

Figure 1. Examples of the exercises, from the examination test, presented.

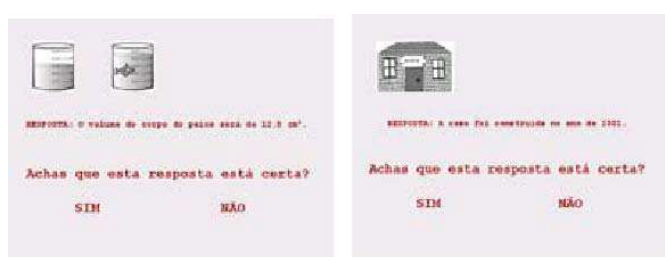

Figure 2. Examples of the answers provided.

The number of presented stimulus was different through the levels: $1^{\text {st }}$ level -24 exercises; $2^{\text {nd }}$ level -16 exercises; and $3^{\text {rd }}$ level -20 exercises.

\section{Method}

Each exercise (Figure 1) was presented on a computer screen followed by the respective possible answer (Figure 2). Participants had to read the exercise text and press a button to answer the question. After reading the provided answer, participants had to press a certain button if the answer was true or another button if the answer was false.

Time spent reading the exercise text and the answer was registered with E-Prime. The accuracy of the answer was also registered. 


\section{Participants}

The sample is constituted by 95 subjects, male and female, aged 9 to 15 years, attending the last levels of the basic cycles in national Portuguese public schools. All the participants were Portuguese native speakers and made their entire schooling in Portugal. Subjects were distributed according to three different levels: $1^{\text {st }}$ level $-32 ; 2^{\text {nd }}$ level -33 ; and $3^{\text {rd }}$ level -30 .

\section{Results}

We classified all the exercises for the following variables: Thematic Domain, Mathematical Operation Type, Number of words on the exercise text, Number of words on the answer text, Number of images on the exercise text, and Number of images on the answer text. These variables were contrasted to the participants' behaviour: Time spent on the exercise text, Time spent on the answer text, and Number of right answers.

First cycle results show that the higher number of subjects' right answers $(91 \%)$ occurs in numbers recognition, specifically roman numbers reading and the area with worst results $(38 \%)$ was estimative calculation in the Thematic Domain of measures and dimensions. On average, the accuracy of answer is above $50 \%$. In this cycle, there are statistically significant positive correlations between the time spent on the exercise text and the number of words $(p<0,05)$, and between the time spent on the answer exercise and its number of words $(p<0,01)$. The same contrast was also found in the third cycle, but only as far as the exercise text is concerned $(p<0,01)$. In the third cycle, we find in the same Thematic Domain the best and the worst results. For instance, in statistics and probabilities, participants had $93 \%$ in one exercise and $17 \%$ in another.

No correlation of the extension of the text and reading time was found on the second cycle. However, there is a positive correlation between the time spent on the answer text and its number of images, i.e., the higher the number of images in the answer, the higher the time spent on it. More interestingly, there is also a positive correlation between the number of right answers and the number of words of the answer text. This means that the provided answers that have an extended composition are associated with a very high score of subjects' right answers.

In this cycle, we concluded that for the same Mathematical Operation Type participants had different results depending on the Thematic Domain, for instance they had high scores in number and calculus and low scores in proportionalities. 


\section{Discussion}

These preliminary results indicate that although the extension of the exercise text and of the answer influences the time spent on reading and solving the problem, it does not necessarily make the resolution of the exercise harder. In other words, the difficulties in mathematical problems solving, and, concequently, the high level of insucces in this area of knowledge, does not seem to be due to the extension (at least in number of words) of the exercises.

The Mathematical Operation Type and the Thematic Domains are also determinant for the exercise resolution. In all cycles, but with more evidence in the first one, numbers and operations is always the domain with the highest number of right answers.

In face of these results, we will look, in further analyses, into correlations between linguistic complexity of the exercises texts (not always very well controlled) and the dependent variables (time spent on exercise text and on answer text, and accuracy of answer) analysed in this experiment. Besides, we will also contrast the eye movement's data collected while solving the exercises with the exercise characteristics and with the linguistic complexity of the exercises.

\section{References}

Hegarty, M., Mayer, R.E. and Green, C. 1992. Comprehension of arithmetic word problems: evidence from students' eye fixations. Journal of Educational Psyhcology, 84, 76-84.

Hoffman, J. E. 1998. Visual attention and eye movements. In H. Pashler (Ed.) Attention. London: University College London Press.

Kiess, H. and Bloomquist, D. 1985. Psychological research methods: a conceptual approach. Boston: Allyn and Bacon.

Just, M. A. and Carpenter, P. A. 1980. A theory of reading: From eye fixations to comprehension. Psychological Review, 87, 329-354.

Suppes, P. 1990. Eye-movement models for arithmetic and reading performance. In E. Kowler (Ed.), Eye Movements and their Role in Visual and Cognitive Processes, 455-477. New York: Elsevier Science publishing.

Thompson, P. 1992. Notations, conventions and constraints: contributions to effective uses of concrete materials in elementary mathematics. Journal for Research in Mathematics Education, 23, 123-147. 